\title{
Novas perspectivas na preparação de amostras para análise cromatográfica
}

\author{
C. A L M E I A, P. ROSÁRIO, P. S ER ÔDIO, J. M. F. NOGUEIRA*
}

\begin{abstract}
Resumo
A presente contribuição aborda as principais metodologias adoptadas na preparação de amostras complexas para análise cromatográfica, destacando-se a extracção em fase sólida (SPE) e os mais recentes desenvolvimentos nas técnicas isentas em solventes orgânicos, com particular
\end{abstract}

incidência para a micro-extracção em fase sólida (SPME) e a extracção sorptiva em barra de agitação (SBSE) no enriquecimento de compostos orgânicos em diversos tipos de matrizes, exemplificando todo o potencial de aplicação destes novos conceitos a sistemas particulares.

\section{Introdução}

Durante a implementação de métodos cromatográficos, estão genericamente associadas diversas etapas prévias para preparação das amostras, podendo incluir matrizes gasosas (ex. ar, misturas de gases, emissões de plantas, etc.), líquidas (ex. água, misturas de solventes, fluídos biológicos, etc.) ou sólidas (ex. sedimentos, produtos farmacêuticos, polímeros, etc.), consoante o(s) tipo(s) de analito(s) em estudo, nomeadamente, compostos voláteis, semi-voláteis ou não-voláteis. Estas etapas contemplam fundamentalmente a extracção ou enriquecimento dos analitos da matriz, mas também limpeza ou fraccionamento, concentração e em certos casos derivatização, tendo em conta todas as vantagens analíticas inerentes a cada sistema em particular, podendo estes procedimentos envolver até cerca de $80 \%$ do tempo analítico despendido.

O principal objectivo dos métodos de preparação de amostras é transferir os analitos com interesse da matriz original, numa forma mais adequada para introdução na instrumentação cromatográfica, podendo a análise ser directa no caso de estarmos em presença de teo- res significativos ou com recurso a estratégias para o enriquecimento de traços vestigiais, no sentido de ganho de sensibilidade.

Do ponto de vista da análise de compostos orgânicos voláteis $\left(\mathrm{VOCS}^{1}\right)$, o espaço de cabeça estático (SHS) e dinâmico (DHS ou purge \& trap) são as metodologias correntemente utilizadas desde há largos anos, para enriquecimento de matrizes líquidas e sólidas. Por outro lado, a extracção líquido-líquido (LLE) convencional tem sido a técnica de eleição em química analítica nas últimas décadas, particularmente usada no enriquecimento de compostos orgânicos semi-voláteis, onde o fenómeno de distribuição ou partição $\left(K_{D}=C_{O r g} / C_{A q}\right)$ é descrito por diferenças de polaridade ou solubilidade do(s) analito(s) entre a amostra em estudo, geralmente uma matriz aquosa e uma fase orgânica imiscível (ex. n-hexano, diclorometano, etc.). Para operação laboratorial, a LLE descontínua recorre às tradicionais ampolas de decantação (figura 1 ), requerendo genericamente volumes consideráveis de amostra (0,1-2 L) para ganho de sensibilidade e de solvente orgânico (5-100 mL), no sentido de recuperar eficazmente os analitos com interesse.
O enriquecimento de compostos orgânicos semi-voláteis provenientes de matrizes sólidas pode igualmente ser efectuado por métodos clássicos, concretamente por lixiviação com solventes orgânicos (LSE) ou Soxhlet e mais recentemente com recurso a extracção ultra-sónica (UE), extracção super-crítica (SFE), extracção por solventes acelerada (ASE) e extracção assistida por micro-ondas (MASE).

Contudo, qualquer que seja a metodologia adoptada no enriquecimento de compostos orgânicos semi-voláteis em que estejam pressupostamente envolvidos solventes orgânicos, é imperativo um passo de concentração posterior com o intuito de eliminar o excesso de solvente tendo por objectivo a diminuição dos limites de detecção dos compostos alvo, podendo esta etapa incrementar consideravelmente eventuais contaminantes interferentes. Finalmente, somente parte do extracto resultante é analisado no sistema cromatográfico eleito com recurso a microseringas convencionais. A figura 1, ilustra os principais passos genericamente associados na preparação de amostras para análise cromatográfica com recurso à LLE.

\footnotetext{
${ }^{1}$ Adoptam-se ao longo da presente contribuição abreviaturas dos termos anglicizados (ex. VOC: volatile organic compound) para facilidade de leitura *Laboratório de Cromatografia e Electrofórese Capilar, Departamento de Química e Bioquímica e Centro de Ciências Moleculares e Materiais, Faculdade de Ciências da Universidade de Lisboa, Campo Grande Ed. C8, 1749-016 Lisboa; (nogueira@fc.ul.pt)
} 
figura 1 Principais passos genericamente associados à preparação de amostras para análise cromatográfica com recurso à extracção líquido-líquido.

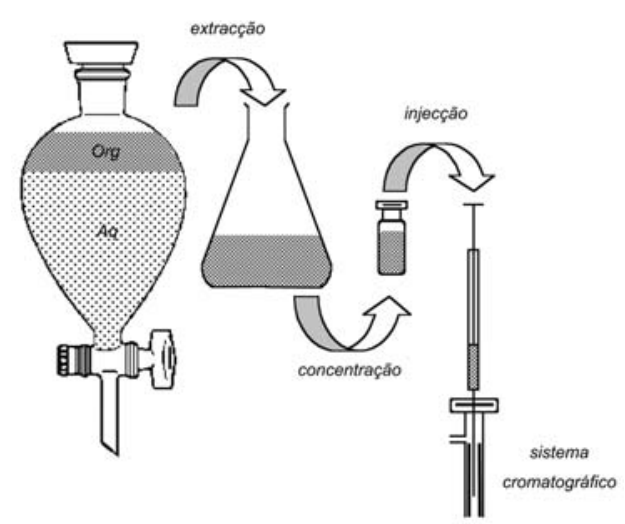

Apesar da abrangência e eficácia demonstradas, as metodologias de preparação de amostras para análise cromatográfica envolvendo solventes orgânicos, já não se coadunam com as actuais exigências de redução do tempo despendido e automatização, necessárias à maior eficácia do trabalho de rotina nos laboratórios analíticos. Por outro lado, a miniaturização tem vindo a assumir-se como tendência dominante em química analítica, sendo cada vez mais implementada em diversos processos de enriquecimento, com o objectivo de reduzir o volume da amostra em estudo. Um exemplo prático, é a aplicação da micro-extracção líquido-líquido ( $\mu$ LLE) no enriquecimento de analitos para injecção directa na instrumentação cromatográfica, embora a sensibilidade alcançada não seja por vezes a mais desejável, particularmente em análise vestigial. A miniaturização permite ainda, facilidade de automatização com possibilidade de acoplamento on-line a instrumentação cromatográfica e hifenada de topo, reduzindo simultaneamente o tempo analítico e o consumo excessivo de solventes orgânicos, contribuindo desta forma para uma maior produtividade dos laboratórios analíticos.

Na actual era da "química verde", as técnicas de preparação de amostras para análise cromatográfica já não se compadecem com o consumo excessivo de solventes orgânicos tóxicos, tendo em vista o impacto ambiental que isso acarreta. Nesta perspectiva, têm surgido novos conceitos aliados a metodologias que conseguem conjugar a miniaturização analítica com redução ou mesmo eliminação do consumo de solventes orgânicos (solventless), para enriquecimento de compostos alvo particularmente de traços em diversos tipos de matrizes. Destacam-se neste contexto, a já largamente estabelecida extracção em fase sólida e mais recentemente, a micro extracção em fase sólida e a extracção sorptiva em barra de agitação, que para além de reduzirem a manipulação analítica, proporcionam significativa sensibilidade na recuperação de analitos alvo, elevada reprodutibilidade, rapidez, baixo custo e facilidade de automatização.

A presente contribuição visa uma abordagem a estes novos conceitos de preparação de amostras para análise cromatográfica, exemplificando as principais vantagens analíticas na aplicação destas metodologias a sistemas particulares.

\section{Extracção em fase sólida}

O conhecimento das propriedades adsorptivas das superfícies sólidas remonta a várias décadas atrás, tendo a utilização do carbono activado no tratamento e purificação da água para o consumo Humano na década de cinquenta, incentivado a aplicação da técnica de extracção em fase sólida (SPE) no isolamento e análise de compostos orgânicos em matrizes aquosas. O desenvolvimento de novos materiais sólidos, estimulou o recurso à técnica de SPE nas décadas de sessenta e setenta, tendo sido introduzidos polímeros, o primeiro dos quais o poliestireno. A sílica ligada, como por exemplo a octadecilsilica (C18), revolucionou a utilização da técnica de SPE e rapidamente se tornou num material de eleição para diversos tipos de aplicações. Os estudos até hoje efectuados, revelaram que este material é indicado para uma grande variedade de compostos com diversa polaridade, possuindo elevada capacidade de retenção. No entanto, após desenvolvimento e larga aplicação da técnica de SPE, ficou bem patente que não existe um material sólido universal capaz de reter tipos de compostos significativamente distintos nas mais diversas aplicações. Muitos dos materiais são seleccionados consoante o objectivo em estudo, área de trabalho ou famílias particulares de compostos semi-voláteis e não-voláteis que se pretendam analisar e neste sentido incrementar selectividade.

Os actuais tipos de enchimentos sólidos devem ser seleccionados de acordo com os mecanismos de retenção pretendidos, podendo genericamente ser classificados como apolares (ex. octadecil, octil, fenil, etc.), polares (ex. cianopropil, diol, etc.), de troca-iónica (ex. trimetilaminopropil, carboximetil, etc.), adsorção (ex. silica-gel, florisil, carvão grafitizado, etc.), covalentes (ex. ác. fenilborónico) ou múltiplos, baseados na interacção analito/enchimento ou somente na natureza do(s) analito(s) em estudo. Nos enchimentos apolares ou de fase reversa, ocorrem interacções devidas às forças de van der Waals de tipo hidrofóbico e nos polares ou de fase normal, interacções de tipo hidrofílico através de dipolos espontâneos ou induzidos e por pontes de hidrogénio. Nos enchimentos de troca iónica, ocorrem atracções electrostáticas entre o(s) analito(s) e o grupo carregado da fase sólida, enquanto que nos de adsorção, a retenção do(s) analito(s) alvo ocorre nos centros activos superficiais dos materiais constituintes do enchimento.

Existem no mercado dois formatos de dispositivos ou invólucros para imple- 

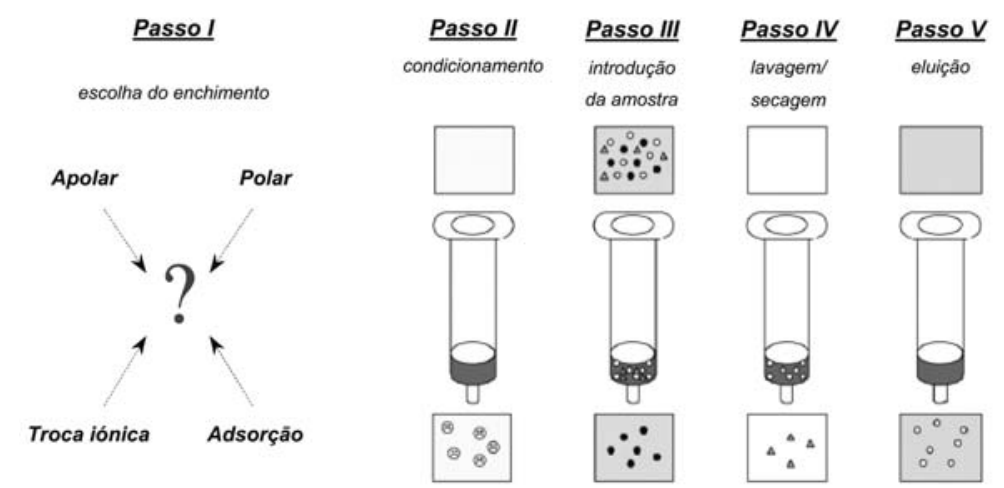

figura 2 Principais passos genericamente associados à extracção em fase sólida com recurso a cartuchos.

mentar a SPE, nomeadamente, em cartucho de polipropileno ou vidro (figura 2) e em disco, possuíndo este último enchimentos com tamanho de partícula inferior, genericamente compreendido entre 8 e $40 \mu \mathrm{m}$. Esta característica, proporciona uma maior capacidade de retenção dos analitos alvo e consequentemente, maior reprodutibilidade com redução do tempo analítico quando são utilizados grandes volumes de amostra.

Actualmente, a SPE é uma técnica vulgarizada, utilizada para extracção, concentração e limpeza (clean-up) do(s) analito(s) com interesse de diversos tipos de matrizes. O manuseamento desta técnica, consiste num conjunto de passos que normalmente tem início na escolha do formato e capacidade do dispositivo para SPE, relacionada com o volume da amostra, selecção e quantidade (50-1.000 mg) do enchimento adequado à natureza do meio e à retenção completa do(s) analito(s) em estudo. Um factor determinante na selecção e quantidade do enchimento é o volume de breakthrough durante a preparação das amostras, relacionado com a ineficiente retenção dos analitos ou com fenómenos de saturação do enchimento quando são eluídos grandes volumes de amostra, com o consequente prejuízo nas respectivas recuperações. Um segundo passo, consiste no condicionamento do enchimento com a finalidade de o activar, sendo determinado pela natureza do analito, aplicando-se o princípio de "polar dissolve polar". No caso da presença de analitos polares, podem ser utilizados cartuchos contendo enchimentos com características de fase normal, no caso de analitos apolares, seleccionam-se enchimentos com ca- racterísticas de fase reversa. A título de exemplo, para analitos apolares podem ser seleccionados enchimentos constituídos por octadecilsilica, sendo genericamente utilizado metanol/água para o correspondente condicionamento. Num terceiro passo, a amostra cujo volume pode ser de alguns mililitros até algumas centenas de mililitros, é adicionada ao dispositivo de SPE, podendo ainda ser vantajoso o controlo do $\mathrm{pH}$ ou da força iónica para a retenção mais efectiva do(s) analito(s) alvo no enchimento seleccionado. No caso de volumes significativos, a aplicação de vácuo torna-se numa ferramenta indispensável, sendo necessário controlar a velocidade do fluxo uma vez a mesma poder influenciar o fenómeno de retenção associado. Um quarto passo, é implementado para limpeza do enchimento com recurso a solventes adequados, no sentido de remover potenciais interferentes indesejáveis. Após secagem, um quinto e último passo é implementado com o intuito de eluir ou remover os compostos alvo retidos no enchimento, sendo seleccionado um solvente com polaridade adequada, cujo volume pode ir de algumas centenas de microlitros a alguns mililitros, consoante o teor e as características de polaridade do(s) analito(s) envolvido(s). Para uma melhor e mais eficiente eluição, é recomendado que o solvente eleito interaja com o enchimento durante um tempo mínimo necessário. Após concentração para eliminação do solvente no sentido de baixar os limites de detecção do(s) analito(s) em estudo, parte do extracto é então introduzido no sistema cromatográfico com recurso a microseringas. A figura 2 ilustra os principais passos anteriormente enunciados para extracção em fase sólida.
A SPE é uma técnica analítica muito poderosa quer do ponto de vista da selectividade quer mesmo da sensibilidade, muito versátil combinando extracção com limpeza e concentração, relativamente rápida, pouco onerosa e possibilita automatização on-line (ex. Gilson, Zymark, etc.) com instrumentação cromatográfica. O domínio de aplicação da SPE é actualmente muito diversificado, incluindo amostras ambientais, alimentares, biológicas, químicas, bioquímicas, petroquímicas, farmacêuticas, forenses, biomédicas, etc. A figura 3, exemplifica a aplicação da SPE a uma amostra de água proveniente do estuário do rio Mondego, seguido de cromatografia gasosa capilar acoplada à espectrometria de massa no modo de varrimento contínuo (full-scan). É possível verificar a significativa selectividade desta técnica na recuperação de diversos tipos de pesticidas, nomeadamente, molinato $(54,8$ $\mu \mathrm{g} / \mathrm{L})$, clorfenvinfos $(3,0 \mu \mathrm{g} / \mathrm{L})$ e oxadiazão $(<0,1 \mathrm{ng} / \mathrm{L})$, bem como elevada sensibilidade para diferentes níveis vestigiais, evidenciando enorme potencial na monitorização de micropoluentes orgânicos em amostras ambientais.

Nos últimos anos, a SPE tem vindo a substituir quase por completo a LLE, uma vez ter provado ser uma técnica muito poderosa na preparação de amostras para análise cromatográfica, sendo comparativamente de mais rápida e fácil execução, exacta, precisa, consome quantidades reduzidas de solventes orgânicos, não envolve material de custo oneroso, não forma emulsões e apresenta níveis de recuperação significativos. Embora a SPE exija por vezes um procedimento laborioso, apresenta ainda a particularidade dos cartuchos 
figura 3 Traçado de corrente iónica relativo a uma amostra ambiental de água proveniente do estuário do rio Mondego, com recurso a extracção em fase sólida (C18) e análise por cromatografia gasosa capilar com deteç̧ão por espectrometria de massa no modo de varrimento contínuo.

ou discos poderem ser reutilizados em sistemas no qual as amostras não sejam demasiado sujas.

Apesar das vantagens inerentes à SPE, a preparação de amostras para análise cromatográfica direcciona-se cada vez mais no sentido da diminuição do volume de amostra, redução do número de passos analíticos e tempo envolvidos, isenção de solventes orgânicos tóxicos e miniaturização dos sistemas extractivos, fundamentalmente com recurso às inovadoras técnicas de extracção sorptiva.

\section{Técnicas de extracção sorptiva}

Nos últimos anos, as técnicas de preparação de amostras baseadas na extrac-

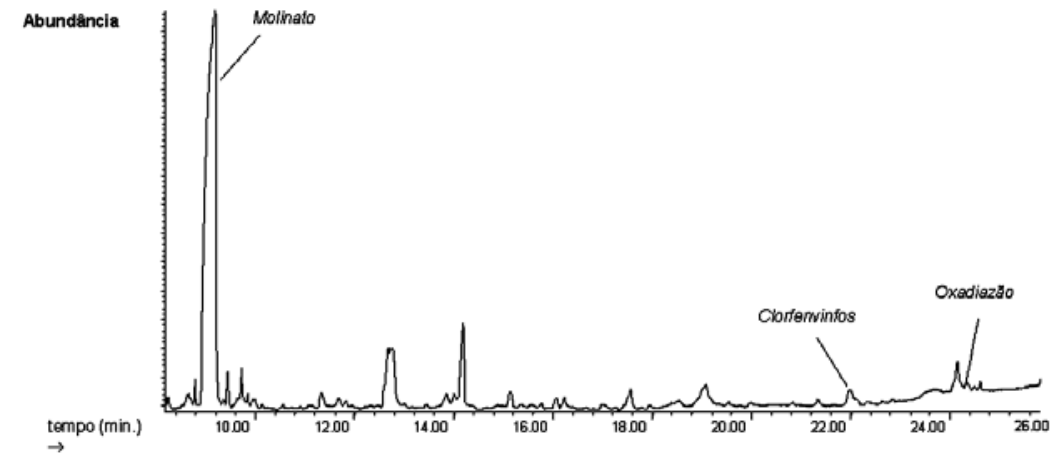

ção sorptiva têm despertado enorme interesse e grande entusiasmo, uma vez que se têm revelado muito promissoras, "amigas do ambiente" e integradas justamente na designada "química verde". Na extracção sorptiva, os analitos são extraídos por exemplo de uma matriz aquosa para um polímero líquido imiscível e contrariamente à SPE, no qual os analitos são retidos à superfície do enchimento, a quantidade total da fase polimérica participa de forma decisiva no fenómeno de enriquecimento.

A fase de extracção mais comum nas técnicas de extracção sorptiva é o polidimetilsiloxano (PDMS), muito conhecido das fases estacionárias usadas nas colunas de cromatografia gasosa, sendo termicamente estável e mais inerte que os materiais adsorventes convencionais, possuindo excelentes propriedades de difusão e tolerando uma vasta gama de temperaturas de operação $\left(220-320^{\circ} \mathrm{C}\right)$. Este material origina ainda baixo ruído instrumental, não promove decomposição dos analitos com interesse e tem a particularidade de poder ser reutilizado.

A extracção sorptiva é por natureza um fenómeno de equilíbrio, no qual o processo de enriquecimento é controlado pelo coeficiente de partição dos analitos entre a fase polimérica e a matriz da amostra, integrando actualmente estas técnicas para além de outras, a microextracção em fase sólida e a extracção sorptiva em barra de agitação. 


\subsection{Micro-extracção em fase sólida}

No início da década de noventa, J. Pawliszyn e colaboradores introduziram uma nova técnica analítica, a micro-extracção em fase sólida (SPME), baseada na sorpção dos analitos presentes por exemplo numa matriz aquosa, para uma fina fibra de sílica fundida revestida por uma camada polimérica. A fibra de SPME, encontra-se colocada num suporte com a forma de uma seringa, podendo ser inserida directamente na matriz da amostra ou no espaço de cabeça acima da mesma como é ilustrado no esquema da figura 4 e seguidamente, introduzida no injector de um sistema cromatográfico gasoso ou líquido. $\mathrm{Na}$ SPME directa, os analitos semi-voláteis ou involáteis difundem-se directamente da matriz da amostra para o revestimento da fibra no qual são concentrados, enquanto que na SPME por espaço de cabeça (headspace), ocorre partição dos analitos voláteis entre a fase vapor e a matriz da amostra, o que permite diminuir significativamente o tempo de extracção, uma vez a velocidade de difusão em fase gasosa ser maior do que em fase líquida. A SPME por espaço de cabeça é essencialmente aplicada na análise de compostos voláteis que se difundem facilmente da matriz em estudo, tornando-se esta opção particularmente interessante no caso da necessidade de derivatização do(s) analito(s) alvo em compostos voláteis. É a geometria cilíndrica da fibra de SPME que permite uma rápida transferência de massa durante a extracção, com a eliminação do recurso a solventes orgânicos tóxicos, permitindo ainda conjugar num único passo simultaneamente, a extracção, a concentração e a introdução dos analitos na instrumentação cromatográfica. A simplicidade de manuseamento, a rapidez, a selectividade e a sensibilidade da SPME bem como o custo associado, tem motivado um crescente número de analistas na eleição desta técnica para análise cromatográfica.

A SPME é uma técnica de equilíbrio, no qual o principio subjacente é a partição dos analitos com interesse entre o revestimento da fibra e a matriz da amostra em estudo, podendo a massa de composto extraído ser calculada através da seguinte expressão:

$$
n=\frac{K_{f s} \times V_{f} \times C_{0} \times V_{s}}{K_{f s} \times V_{f}+V_{s}}
$$

onde $n$ é a massa de analito extraído, $K_{f s}$ o coeficiente de partição do analito entre o revestimento da fibra e a matriz da amostra, $V_{f}$ o volume do revestimento, $V_{S}$ o volume da amostra e $C_{0}$ a concentração inicial do analito na amostra. Como o volume das amostras é em regra geral significativamente superior ao volume do revestimento da fibra, a expressão pode ainda ser simplificada para $n=K_{f s} \times V_{f} \times C_{0}$

Para além da polaridade dos analitos e das características da fase de revestimento, a eficiência de extracção é influenciada por diversos parâmetros, nomeadamente, volume da amostra tempo de extracção, velocidade de agitação, temperatura, força iónica, $\mathrm{pH}$, bem como as condições associadas à desorpção térmica ou líquida na instrumentação cromatográfica. O tempo de extracção deve em regra geral, ser o suficiente para que uma quantidade significativa do(s) analito(s) alvo seja(m) extraído(s) e idealmente durante esse período, atingir-se o equilíbrio de distribuição dos mesmos entre a matriz da amostra e o revestimento da fibra. Em muitos casos, o tempo necessário para atingir o equilíbrio (equilíbrio estático) é relativamente longo, podendo ser reduzido com recurso a agitação magnética ou ultra-sónica (equilíbrio dinâmico), uma vez ser acelerado o processo de difusão dos componentes orgânicos na matriz.

O aumento da temperatura não favorece em geral o processo de sorpção pela fibra, incrementando a solubilidade dos compostos hidrofóbicos na matriz da amostra, ocorrendo este fenómeno para valores superiores à temperatura ambiente. No entanto, para valores da ordem dos $5^{\circ} \mathrm{C}$, ocorre genericamente uma diminuição da massa do(s) composto(s) sorvido(s) pela fibra relativamente à temperatura ambiente, facto que pode ser explicado pelo decréscimo da difusão dos compostos na matriz da amostra.

Um dos aspectos críticos na optimização da SPME é a selecção do tipo de fibra específica para os compostos com interesse analítico. 0 revestimento mais comum à base de PDMS com $100 \mu \mathrm{m}$ de espessura de filme, é essencialmente seleccionado para a análise de compostos com características hidrofóbicas. Por outro lado, fibras à base de poliacrilato (PA) têm igualmente surgido no mercado, sendo mais adequadas na extracção de compostos hidrofílicos, devido à maior polaridade do revestimento. Ainda outro tipo de fibras, cobrindo uma vasta gama de revestimentos, espessuras de filme e polaridades, têm sido de-

Tabela 1. Tipo de fibras usadas na micro-extracção em fase sólida e principais aplicações.

\begin{tabular}{|c|c|c|}
\hline Revestimento & essura de filme & Aplicação \\
\hline $\begin{array}{l}\text { Polidimetilsiloxano } \\
\text { (PDMS) }\end{array}$ & $\begin{array}{l}100 \mu \mathrm{m} \\
30 \mu \mathrm{m} \\
7 \mu \mathrm{m}\end{array}$ & $\begin{array}{l}\text { Compostos orgânicos apolares } \\
\text { (ex. VOCs, PAHs, BTEX, } \\
\text { pesticidas organoclorados) }\end{array}$ \\
\hline $\begin{array}{l}\text { Poliacrilato } \\
\text { (PA) }\end{array}$ & $85 \mu \mathrm{m}$ & $\begin{array}{l}\text { Compostos orgânicos polares } \\
\text { (ex. pesticidas triazínicos e organo } \\
\text { fosforados, fenóis) }\end{array}$ \\
\hline $\begin{array}{l}\text { Polidimetilsiloxano } \\
\text {-divinilbenzeno } \\
\text { (PDMS-DVB) }\end{array}$ & $\begin{array}{l}65 \mu \mathrm{m} \\
60 \mu \mathrm{m}\end{array}$ & $\begin{array}{l}\text { Hidrocarbonetos aromáticos, } \\
\text { aminas aromáticas, VOCs }\end{array}$ \\
\hline $\begin{array}{l}\text { Carboxen-polidimetilsiloxano } \\
\text { (CAR-PDMS) }\end{array}$ & $75 \mu \mathrm{m}$ & VOCs, hidrocarbonetos \\
\hline $\begin{array}{l}\text { Carbowax-polidimetilsiloxano } \\
\text { (CW-DVB) }\end{array}$ & $65 \mu \mathrm{m}$ & $\begin{array}{l}\text { Compostos orgânicos polares } \\
\text { x. álcoois, cetonas, nitroaromáticos) }\end{array}$ \\
\hline
\end{tabular}


figura 5 Traçado de corrente iónica relativo ao espaço de cabeça de uma amostra de flores da alfarrobeira (Ceratonia siliqua L.), obtido por micro-extracção em fase sólida (PDMS) e análise por cromatografia gasosa capilar com detecção por espectrometria de massa no modo de varrimento contínuo.

senvolvidas e actualmente, encontramse disponíveis no mercado para as mais diversas aplicações, como é resumido na tabela 1. Na SPME, as fibras apresentam como vantagem o facto de poderem ser reutilizadas, dependendo no entanto, do tipo de aplicação a que as mesmas são sujeitas, complexidade da matriz da amostra, condições experimentais e cuidados no respectivo manuseamento uma vez serem frágeis, exigindo ainda condicionamento e optimização antes da respectiva utilização.

A quantidade de amostra é obviamente um parâmetro importante, uma vez a massa do(s) composto(s) extraído(s) pela fibra ser função do volume e da concentração inicial. Um outro parâmetro importante é o efeito da força iónica, já que a adição de um electrólito forte (ex. $\mathrm{NaCl}$ ) pode modificar o processo sorptivo, diminuindo drasticamente a solubilidade dos compostos hidrofóbicos na matriz da amostra, fenómeno designado por salting out, resultando no aumento do(s) coeficiente(s) de distribuição e consequentemente numa maior apetência dos mesmos para o revestimento da fibra. É de realçar que durante o processo extractivo, o $\mathrm{pH}$ pode ter igualmente influência nas características químicas dos analitos alvo e consequentemente, ser decisivo na apetência para o material de revestimento da fibra.

A SPME tem sido particularmente aplicada em combinação com cromatografia gasosa na determinação de VOCs e semi-voláteis, nomeadamente, hidrocarbonetos aromáticos, hidrocarbonetos aromáticos policíclicos (PAHs), bifenilos policlorados (PCBs), bem como na análise de diversas classes de pesticidas, aromas e fragrâncias entre outros, em diferentes tipos de matrizes com com-

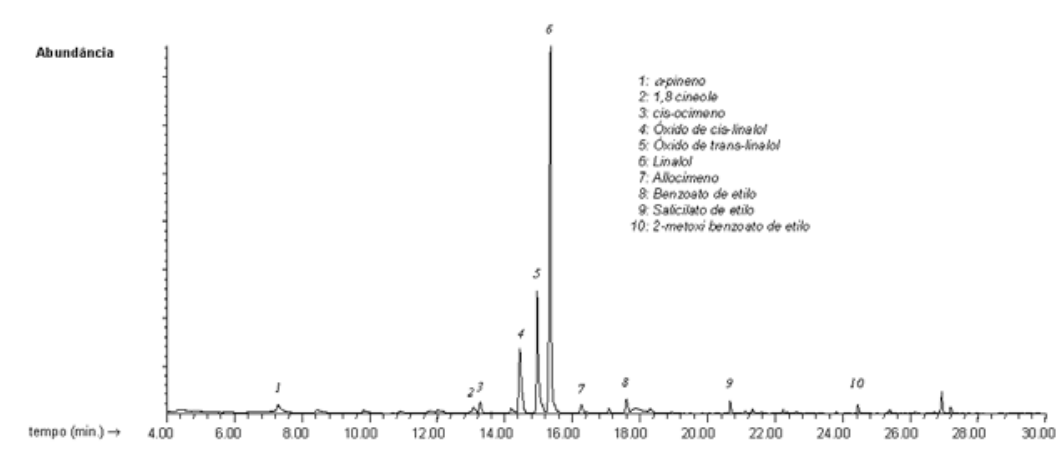

plexidade variável, fundamentalmente de amostras aquosas, bebidas, frutos, plantas, solos, fluídos biológicos, etc. A combinação da SPME com cromatografia líquida, tem-se revelado igualmente muito promissora particularmente na análise de compostos não voláteis ou termolábeis.

A figura 5, exemplifica o potencial de aplicação da SPME no espaço de cabeça de voláteis de flores da alfarrobeira (Ceratonia siliqua L.), seguida de análise por cromatografia gasosa capilar acoplada à espectrometria de massa no modo de varrimento contínuo. É de realçar a ocorrência maioritária de monoterpenos oxigenados e esteres benzílicos, evidenciando todo o potencial de aplicação desta técnica no estudo de compostos voláteis com influência no processo de polinização das plantas.

Actualmente, apesar da técnica de SPME já permitir automatização, a grande limitação que apresenta é a reduzida quantidade de material polimérico envolvido. Para uma fibra típica de $100 \mu \mathrm{m}$ em PDMS, a mais frequentemente utilizada, o correspondente volume é de aproximadamente $0,5 \mu \mathrm{L}$. Consequentemente, a eficiência de extracção de analitos ao nível vestigial em matrizes complexas pode ser drasticamente limitada. Com base nestas considerações, foi recentemente concebida e desenvolvida a extracção sorptiva em barra de agitação, como técnica inovadora, muito sensível e poderosa no enriquecimento de compostos orgânicos vestigiais para análise cromatográfica.

\subsection{Extracção sorptiva em barra de agitação}

A extracção sorptiva em barra de agitação (SBSE), é uma nova técnica de pre- paração de amostras inicialmente proposta por P. Sandra e colaboradores no final dos anos noventa, para enriquecimento de compostos orgânicos de matrizes aquosas.

Uma barra de agitação, constituída por um magnete envolto numa fina película de vidro revestido por um filme em PDMS como é ilustrado na figura 6 (a), é colocada na amostra sob agitação, por forma a promover o movimento de rotação na matriz líquida e simultaneamente a extracção dos analitos para a camada polimérica em condições experimentais optimizadas (figura 6 (b)).

Em analogia com a SPME, as condições experimentais da SBSE têm de ser optimizadas para cada tipo específico de aplicação. Para além das características de polaridade dos analitos e da fase de revestimento, a eficiência de recuperação é igualmente influenciada por parâmetros como o tempo de extracção, a velocidade de agitação, temperatura, força iónica e pH, no sentido do(s) analito(s) com interesse atingirem o equilíbrio de distribuição entre a matriz da amostra e o revestimento polimérico.

Após um determinado período de agitação, a barra é posteriormente inserida num tubo de vidro e colocada numa unidade de desorpção térmica (TD) on-line com um injector de temperatura programada, onde os analitos voláteis e semivoláteis são termicamente desorvidos, sendo posteriormente criofocados e analisados por cromatografia gasosa. Alternativamente, a barra pode ser colocada num volume reduzido $(0,1-2 \mathrm{~mL})$ de um solvente orgânico polar compatível com o PDMS para desorpção líquida (LD), por forma a promover a retroextracção eficaz dos analitos da barra sem destruir a fase polimérica, seguido de 
análise por cromatografia gasosa ou líquida. Em condições não agressivas, as barras de agitação apresentam como vantagem o facto de poderem efectuar dezenas ou mesmo centenas de extracções consecutivas sem manifestarem sinais de deterioração, podendo a SBSE ser genericamente aplicada directamente na matriz da amostra ou alternativamente no espaço de cabeça.

A SBSE baseia-se nos mesmos princípios de equilíbrio da SPME e estudos recentes, demonstraram que existe uma notável correlação entre os coeficientes de partição, relativos à distribuição dos analitos entre a fase de PDMS e a matriz aquosa $\left(K_{P D M S / W}\right)$ e os coeficientes de distribuição octanol-água $\left(K_{0 / w}\right)$, o qual constitui uma medida da polaridade dos compostos orgânicos e fornece uma boa indicação da eficiência de extracção para cada soluto. Ainda que de uma forma grosseira, analitos apolares podem ser caracterizados por valores de $\log K_{O N}$ superiores a 4 e para analitos polares, o log $K_{O W}$ é normalmente inferior a 2 .

O coeficiente $K_{P D M S}$, é por definição a razão entre a concentração do analito na fase de PDMS ( $C_{P D M S}$ ) e na fase aquosa $\left(C_{W}\right)$, após o equilíbrio ser atingido. Este parâmetro pode ser calculado através da razão entre a massa do analito na fase de PDMS ( $m_{P D M S}$ ) e na fase aquosa $\left(m_{W}\right)$, multiplicada pela relação de fase $(\beta)$, que relaciona o volume de amostra aquosa $\left(V_{w}\right)$ e o volume em PDMS $\left(V_{P D M S}\right)$, como é expresso na equação (1). Assim, a eficiência de extracção ou recuperação expressa em percentagem, pode ser calculada através da razão entre a quantidade de analito extraída $\left(m_{S B S E}\right)$ e a existente inicialmente na amostra $\left(m_{0}\right)$, como é descrito pela equação (2). Esta relação permite ainda estimar a recuperação para um dado analito, sabendo o respectivo $\log K_{o w} \mathrm{e}$ a relação de fase $(\beta)$ envolvida. Dependendo do $K_{O N}$, os compostos são extraídos em maior ou menor extensão e quanto maior for a quantidade de PDMS, menor é a relação de fase e consequentemente, mais elevada será a eficiência de extracção.

Conforme pode ser demonstrado, na SBSE a eficiência de extracção dos ana-

(b)

(a)
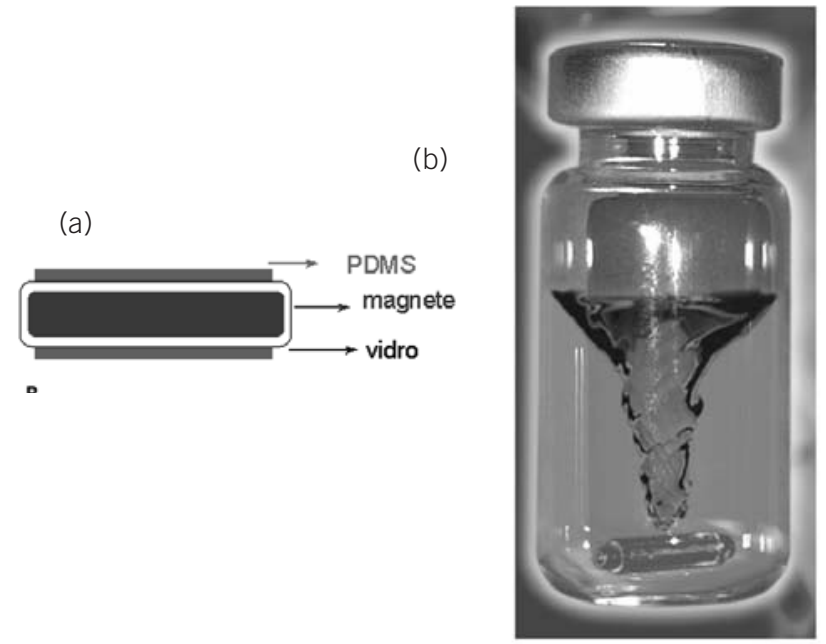

figura 6 Representação esquemática dos constituintes de uma barra de agitação usada na SBSE (a) e durante o processo de extracção (b).

litos é genericamente descrita no equilíbrio pelos coeficientes $K_{0, W}$, incrementando substancialmente a sensibilidade analítica relativamente à SPME, devido ao maior conteúdo em PDMS envolvido, permitindo assim diminuir os limites de detecção e proporcionar todas as vantagens analíticas particularmente em análise vestigial.
Contrariamente à SPME, para a qual já existem no mercado diversos tipos de revestimentos poliméricos, na SBSE apenas se encontram comercializadas barras de agitação revestidas com PDMS contendo um volume compreendido entre 24 e $126 \mu \mathrm{L}$, apresentando no entanto, uma quantidade substancialmente superior à disponibilizada na fibra de

$$
K_{\mathrm{OW}} \approx K_{P D M S}=\frac{C_{P D M S}}{C_{W}}=\left(\frac{m_{P D M S}}{m_{W}}\right) \times\left(\frac{V_{W}}{V_{P D M S}}\right)=\left(\frac{m_{P D M S}}{m_{W}}\right) \times \beta
$$

Eficiência $(\%)=\left(\frac{m_{\text {PDMS }}}{m_{0}}\right) \times 100 \%=\left(\frac{\left(\frac{K_{\text {ON }}}{\beta}\right)}{1+\left(\frac{K_{\text {ON }}}{\beta}\right)}\right) \times 100 \%$

A figura 7, reproduz justamente este comportamento, ilustrando a eficiência obtida por SBSE comparativamente à SPME em função do log $K_{\text {O/W }}$, demonstrando que a primeira é bem descrita pelos coeficientes, sendo a recuperação extractiva quantitativamente superior em idênticas condições experimentais. De acordo com a literatura, para analitos com valores de log $K_{\text {ow }}$ superiores a 3 , são normalmente obtidas recuperações quantitativas por SBSE. No entanto, no caso de extracção incompleta, que genericamente pode ocorrer para compostos com log $K_{\text {ow }}$ inferior a 3 ou ainda em situações de não equilíbrio, a calibração continua a ser válida na SBSE.
SPME mais comum $(0,5 \mu \mathrm{L})$. A maior relação de fase entre a matriz da amostra e o PDMS, proporciona desta forma um aumento da capacidade extractiva e consequentemente, da sensibilidade da técnica de SBSE para uma ordem de grandeza compreendida entre 50 e 250, comparativamente à SPME.

A SBSE tem vindo a ser desenvolvida com sucesso na análise de diverso(s) tipo(s) de matriz(es) complexas, fundamentalmente, ar, águas, bebidas, fluídos biológicos, etc., sendo maioritariamente usada na monitorização de vocs e semivoláteis por desorpção térmica seguida de cromatografia gasosa. Várias aplicações têm sido implementadas com êxito 
figura 7 Comparação da eficiência extractiva por SPME (PDMS: 0,5 $\mu \mathrm{L}$ ) e SBSE (PDMS: $47 \mu \mathrm{L}$ ) em função do coeficiente de partição octanolágua, em idênticas condições experimentais.

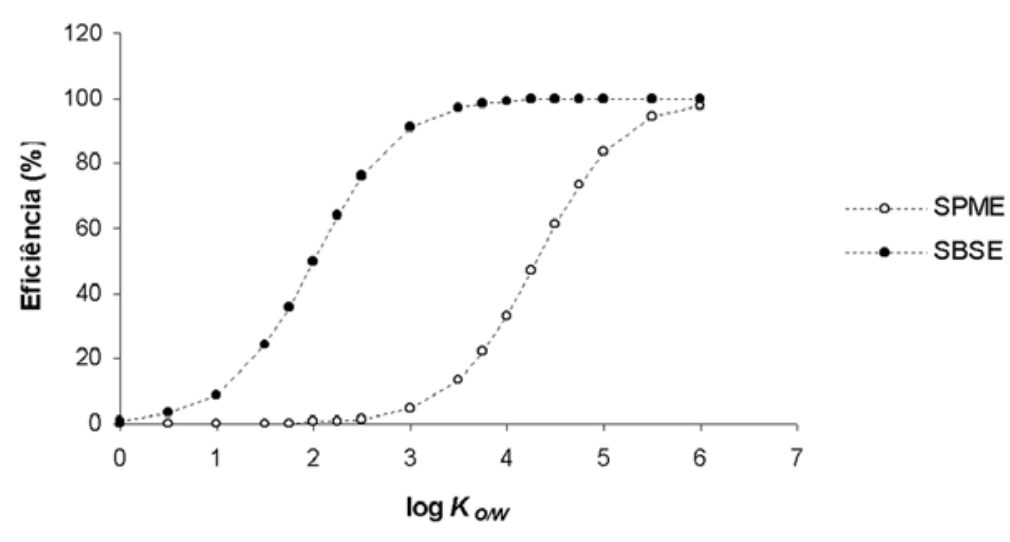

sempenham um papel determinante no respectivo bouquet.

A combinação da SBSE com retroextracção e análise por cromatografia líquida, pode igualmente estender-se na análise de compostos não voláteis ou termolábeis. A figura 9, ilustra uma aplicação por SBSE (PDMS: $126 \mu \mathrm{L}$ ) durante um período de 120 minutos (750 rpm; $\mathrm{T}=20^{\circ} \mathrm{C}$ ), a uma amostra (30 mL; $20 \%$ $\mathrm{NaCl}$ ) de água fortificada com hormonas esteróides a um nível de $10 \mu \mathrm{g} / \mathrm{L}$, seguida de desorpção líquida com acetonitrilo e análise de $30 \mu \mathrm{L}$ por cromatografia líquida de alta eficiência com detecção por ultravioleta/visível. É possível observar a elevada sensibilidade obtida por SBSE, evidenciando vasta abrangência e todo o potencial analítico.

O modo de desorpção líquida permite igualmente ser combinado com análise por cromatografia gasosa, exigindo-se neste caso o recurso a injecções de grandes volumes por forma a incrementar sensibilidade. Este modo apresenta ainda a vantagem de ser menos onerosa que a desorpção térmica, para além das amostras em estudo poderem ser reanalisadas. A figura 10 exemplifica a aplicação da SBSE (PDMS: $47 \mathrm{~mL}$ ) durante 60 minutos $\left(750 \mathrm{rpm} ; \mathrm{T}=20^{\circ} \mathrm{C}\right)$, a uma amostra (30 mL; 5\% metanol) de água para consumo humano, fortificada com pesticidas organoclorados a um nível de 0,1 $\mu \mathrm{g} / \mathrm{L}$, seguida de retroextracção com acetonitrilo e análise de 20 $\mu \mathrm{L}$ por cromatografia gasosa capilar acoplada à espectrometria de massa no modo de monitorização de iões seleccionados (SIM). É possível observar a elevada sensibilidade obtida por esta metodologia na análise multi-componente de pesticidas organoclorados para aquele nível de concentração, adequando-se inequivocamente à directiva da União Europeia (98/83/EC) relativa à qualidade da água para consumo Humano, que estabelece que o valor máximo admissível para pesticidas individuais seja de $0,1 \mu \mathrm{g} / \mathrm{L}$ e a soma total não possa exceder $0,5 \mu \mathrm{g} / \mathrm{L}$. Verifica-se com recurso a esta metodologia, que limites de detecção da ordem dos baixos ng/L podem ser alcançados na monitorização de pesticidas em amostras de água e justamente atender em conformidade com aquela directiva. figura 8 Traçado de corrente iónica relativo a uma amostra de vinho da Madeira (Verdelho/1999) obtido por extracção sorptiva em barra de agitação (PDMS: $47 \mu \mathrm{L}$ ) seguida de desorpção térmica e análise por cromatografia gasosa capilar com detecção por espectrometria de massa no modo de varrimento contínuo.

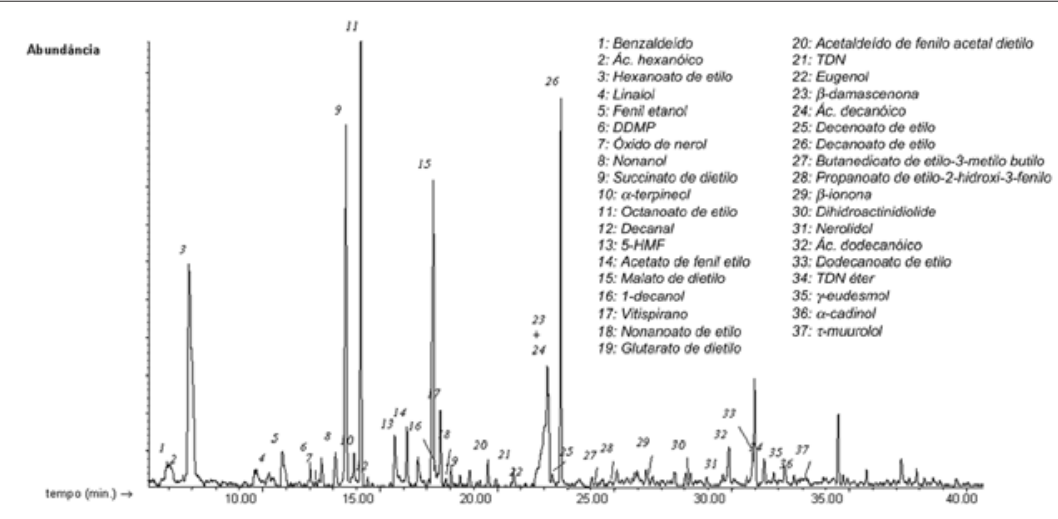



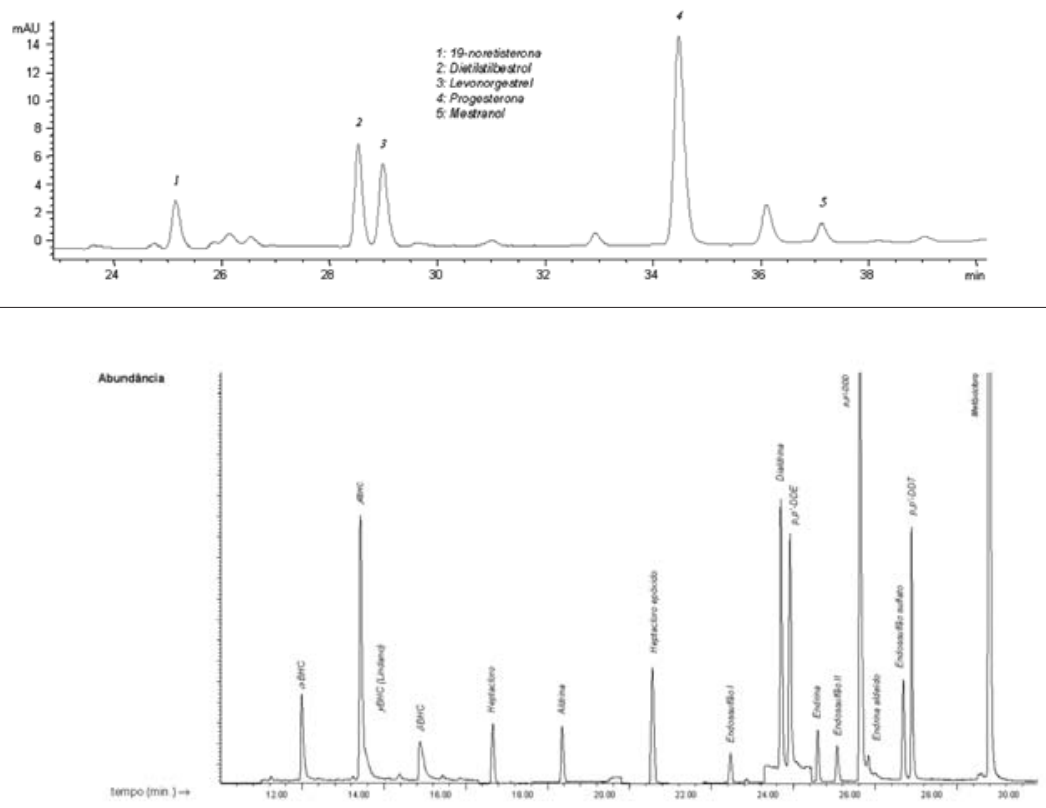

figura 9 Cromatograma relativo a uma amostra de água fortificada com uma mistura de hormonas esteróides a um nivel de $10 \mu \mathrm{g} / \mathrm{L}$, obtida por extracção sorptiva em barra de agitação seguida de desorpção líquida e análise por cromatografia líquida de alta eficiência com detecção por ultravioleta/visivel $(\lambda=240 \mathrm{~nm})$

\section{Perspectivas futuras}

A aplicação das técnicas de extracção sorptiva na preparação de amostras para análise cromatográfica encontra-se em franca evolução. O interesse e aceitação destas metodologias têm-se manifestado através de um número crescente de estudos publicados sobre inúmeras aplicações. Genericamente, requerem volumes reduzidos de amostra, a análise é directa não exigindo múltiplos passos analíticos, são isentas de solventes orgânicos tóxicos, apresentam simplicidade e facilidade de manipulação, rapidez, baixo custo, elevada sensibilidade e possibilitam automatização a instrumentação analítica de topo.

Será de antever, que esta tendência se mantenha num futuro próximo, com o desenvolvimento de novos materiais poliméricos para sorpção e conceitos ino- vadores aliados à instrumentação analítica, capazes de tornar as técnicas de extracção sorptiva ainda mais abrangentes e eficazes, fundamentalmente em análise multiresíduo de níveis vestigiais de várias classes de compostos em diversos tipos de matrizes.

\section{Bibliografia}

S. Moldoveanu, V. David, Sample Preparation in Chromatography, Journal of Chromatography Library, Vol. 65, Elsevier, Amesterdam, 2001.

R. Soniassy, P. Sandra, C. Schlett, Water Analysis - organic micropollutants, HewlettPackard, USA, 1994.

I. Liska, Fifty Years of Solid-Phase Extraction in Water Analysis - historical development and overview; J. Chromatogr. A, 885 (2000) 3.

D. Barceló, Sample Handling and Trace Analysis of Pollutants - techniques, applica- figura 10 Fragmentograma de massa relativo a uma amostra de água para consumo Humano fortificada com uma mistura de pesticidas organoclorados a um nível de 0,1 $\mu \mathrm{g} / \mathrm{L}$, obtida por extracção sorptiva em barra de agitação seguida de desorpção líquida e análise por cromatografia gasosa capilar com detecção por espectrometria de massa no modo de monitorização de iões seleccionados. tions and quality assurance, Vol. 21, Elsevier Science, Amsterdam, 2000.

J. Pawliszyn, Solid Phase Microextraction theory and practice, Wiley-VCH Inc., Canada, 1997.

E. Baltussen, P. Sandra, F. David, C. Cramers, Stir Bar Sorptive Extraction (SBSE), a Novel Extraction Technique for Aqueous Samples: theory and principles, J. Microcolumn. Sep., 11 (1999) 737

E. Baltussen, C. Cramers, P. Sandra, Sorptive Sample Preparation - a review, Anal. Bioanal. Chem., 373 (2002) 3.

F. David, B. Tienpont, P. Sandra, Stir Bar Sorptive Extraction of Trace Organic Compounds from Aqueous Matrices, LC-GC Europe, 16 (2003) 410

P. Serôdio, J.M.F. Nogueira, Multi-residue Screening of Endocrine Disrupters Chemicals in Water Samples by Stir Bar Sorptive Extraction-Liquid Desorption-Capillary Gas Chromatography-Mass Spectrometry Detection, Anal. Chim. Acta, 517 (2004) 21

Actualidades Científicas

\section{Oxigénio}

Demonstrar que um ambiente inerte e selado não foi contaminado com oxigénio foi até ao momento um desafio tecnológico. No entanto, um grupo de investigadores da Universidade de Strathclyde, Reino Unido, desenvolveu uma nova formulação que, a partir do momento em que é activada por radiação UV-A, transforma-se num indicador irreversível da presença de oxigénio (SK. Lee et al., Chem. Commun. (2004) 17, 1912)

Sendo o oxigénio um participante essencial nas reacções químicas que aceleram a degradação de alimentos, a utilização desta nova formulação em embalagens alimentares proporcionará a sua detecção por inspecção visual, fornecendo aos consumidores um indi- cador do respectivo estado de conservação. Está também previsto que os benefícios provenientes desta nova formulação possam ser estendidos a outros materiais/bens de consumo embalados que necessitem de atmosfera modificada, nomeadamente produtos farmacêuticos e peças arqueológicas (adaptado de Chemical Science (2004) 1, C68). 